\title{
Caillet Bois, director del Instituto y organizador de las Jornadas de métodos de investigación y enseñanza de la historia rioplatense y en Estados Unidos
}

\author{
Caillet Bois, director of the Institute and organizer of the conferences on research methods and teaching of River Plate \\ history and in the United States.
}

Sandra Sauro

Facultad de Filosofia y Letras - Universidad de Buenos Aires - Programa de Investigaciones en Historiografia Argentina (PIHA) - Instituto de Investigaciones Historicas "Dr. Emilio Ravignani", Argentina sgsauro@gmail.com

\begin{abstract}
RESUMEN:
Caillet Bois participa en la organización de las Jornadas de métodos de investigación y enseñanza de la historia rioplatense y en Estados Unidos. Colabora la Comisión Fullbright y el profesor Roland T. Ely quien presenta un programa académico sobre el que se basarán las jornadas realizadas entre 1966 y 1971 . La continuidad de los encuentros, el dictado de cursos, la oferta de becas y los cambios geopolíticos, contribuyen a explicar la introducción y consolidación de los estudios de la historia de Estados Unidos en algunas universidades argentinas. Se intentará pasar revista al conjunto de trabajos presentados en estas seis reuniones académicas. Palabras Clave: Estados Unidos, Caillet Bois, Roland Ely, Fullbright, Historiografía erudita.
\end{abstract}

\begin{abstract}
:
Caillet Bois participates in the organization of the conferences on research and teaching methods of River Plate history and in the United States. The Fulbright Commission and Professor Roland T. Ely collaborate and present an academic program on which the seminars held between 1966 and 1971 will be based. The continuity of the meetings, the teaching of courses, the offer of scholarships and the geopolitical changes contribute to explain the introduction and consolidation of the studies of the history of the United States in some Argentine universities. An attempt will be made to review the set of papers presented in these six academic meetings.
\end{abstract}

KEYwords: United States, Caillet Bois, Roland Ely, Fullbright, Scholarly historiography.

\section{INTRODUCCIÓN}

Entre los años de 1955 y 1958 la Universidad de Buenos Aires atravesó por un breve período de transformación académica, que sin abandonar los principios de la Reforma de 1918, aspiraba a instaurar un modelo de modernización. En esa misma línea, la Facultad de Filosofía y Letras, incluyendo la Carrera de Historia, intentó entre 1957 y 1965 un proyecto de reforma de planes de estudio e incorporación de nuevas materias. Con el golpe de estado de Onganía en 1966 se abre una etapa política que frustra el proyecto de renovación discontinuando los cambios alcanzados hasta entonces en la universidad, la facultad y la carrera.

El trabajo que aquí se presenta se inscribe en esta especial coyuntura de 1966 signada por el onganiato y la intervención de las fuerzas policiales en la universidad conocida como la Noches de los Bastones Largos. Entre 1966 y 1971 se desarrollan las seis jornadas de métodos de investigación y enseñanza de la historia rioplatense y en Estados Unidos que se exploran en este artículo. Las cinco primeras, organizadas por el Instituto de Historia Argentina y Americana y el Instituto de Literatura Argentina en forma conjunta, tuvieron como sede diferentes universidades del país. La VI a pesar de haber sido organizada por la Asociación de Estudios Americanos, mantiene en la presidencia a los directores de los Institutos organizadores de las cinco 
primeras, el profesor Ricardo Caillet-Bois y profesor Delfín Garasa respectivamente. Como antecedente de la realización de estas jornadas puede mencionarse el dictado de seminarios y cursos en la Carrera de Historia de la FFyL-UBA. La continuidad de los encuentros y el dictado de los cursos, más la oferta de becas y los cambios geopolíticos, contribuye a explicar la introducción y consolidación de los estudios de la historia de Estados Unidos en las universidades argentinas.

En la correspondencia institucional (AIR 93 y AIR 116) y en las publicaciones del Boletín del Instituto de Investigaciones Históricas de la FFyL/UBA se constata la presencia del grupo erudito que llevaba adelante la organización de las jornadas y gestionaba los seminarios. En las cartas puede leerse la dinámica y los avances que va dando forma estas actividades. El temario propuesto para la primera jornadas prioriza el estudio de las tesis de frontera y su aplicabilidad en la historia argentina; la influencia del pensamiento constitucional norteamericano en el Río de la Plata; la necesidad de relacionar la historia de América; la actualización de las investigaciones históricas y su aplicabilidad en la enseñanza secundaria y primaria. En correlación con las jornadas la correspondencia institucional destaca la colaboración del Profesor Roland T. Ely y de la Comisión Fullbright así como la solicitud para obtener la visita de un profesor de Historia de los Estados Unidos para el año académico 1967.

El trabajo que el profesor Roland T. Ely presenta en las Primeras Jornadas constituye un verdadero programa académico que sin duda, servirá de base a la organización de las demás jornadas promovidas por los historiadores eruditos entre 1966 y 1971. Esa comunicación fue publicada como artículo en el Boletín del Instituto en el año 1969. También se publicaron las actas de las seis jornadas y los comentarios que ellas suscitaron. Sobre este conjunto documental se intentará pasar revista al conjunto de trabajos presentados en este evento académico. Asimismo, sobre la base de las fuentes relevadas, se procurará dar contenido empírico a la estrecha relación que cruza los intereses y las intenciones de la política y de la historia. Para esto, esta investigación pone en correlación las partes I y II de la ponencia del Profesor Ely con las comunicaciones y ponentes presentados en las jornadas durante sus años de realización. Se sostiene como hipótesis central que el programa académico del profesor norteamericano está sustentado en objetivos académicos (historia) y no-académicos (política), por lo tanto, persigue intereses que involucra actividades académicas y otras que actúan por fuera de ellas. En las reflexiones finales se intenta identificar, distinguir y vincular estos objetivos.

Para cerrar esta introducción es preciso recordar cuales eran las corrientes historiográficas que dominaban el contexto internacional desde 1950-1960 (Iggers, 1995: 42-58 y 76-82). En Europa occidental, los modelos de Annales y del marxismo inglés constituían los paradigmas de referencia. El primero, surgido a partir de la Revista Annales fundada en 1929 por Lucíen Febvre y Marc Bloch, tendrá como protagonista a Fernando Braudel en las décadas siguientes a la segunda posguerra. Como figura destacada y reconocida en el ámbito internacional, intenta poner en diálogo a la historia con las ciencias sociales. Por otro lado, la corriente marxista de los historiadores británicos se enfocará en los estudios de la historia social y económica. Finalmente, la historia económica practicada en los Estados Unidos conocida como cliometría. Inspirada en teorías económicas neoclásicas, pone a la historia al servicio de la economía para construir modelos únicos de desarrollo de base empírico-cuantitativo. Resultó por lo tanto, funcional al clima político de la Guerra Fría y desató una clara confrontación ideológica contra el comunismo.

La influencia o recepción de estas corrientes en el contexto ha sido estudiada y documentada desde hace algunos años en trabajo pioneros que se ocuparon de abordar estas relaciones. (Devoto, 1994; Míguez: 1994). El objetivo de este artículo no va en esa dirección aunque puede percibirse en las fuentes consultadas este clima de época: coyuntura en la que emerge la renovación con la historia social y económica en tensión con las producciones más tradicionales en clave política. Asimismo, pueden asociarse con cada grupo de historiadores locales algunos referentes e interlocutores internacionales y el tejido de sus redes de sociabilidad. 


\section{Contexto histórico internacional y en Argentina, décadas del 50 y 60}

El contexto de la primera posguerra inicia un período de fuertes tensiones entre las naciones protagonistas de la contienda, situación que busca disiparse por la vía diplomática y cultural. Entre las diferentes estrategias implementadas, la educación fue vista como un recurso fundamental para fomentar la paz y contrarrestar la xenofobia. Ya en 1916, el Segundo Congreso Científico Panamericano celebrado en Washington pone atención en el eje de la Historia. Recomienda la creación de cátedras de historia en las universidades de los Estados Unidos, junto con el desarrollo e ideales de los pueblos latinoamericanos. Como contraparte, en las universidades de la América Latina, cátedras de historia, ideales y desarrollo del pueblo de Norte América. Esta propuesta no tuvo la aceptación esperada y recién será retomada a fines de la década de los años 30. Desde la Unión Panamericana se realizan una serie de encuentros, congresos y convenciones entre los que se promueve la revisión de manuales y se discute acerca de la enseñanza de la disciplina con alcance regional. En tal sentido cabe mencionar la creación en 1929 del Instituto Panamericano de Geografía e Historia (IPGH) y la Convención sobre la Enseñanza de la Historia realizada en Montevideo en 1933. Dentro de estas propuestas se estimula la creación de comisiones nacionales que adhieran a la revisión de manuales escolares.(Pita González, A. y Ventura Ramírez, R: versión on line). Los congresos de americanistas resultaron otro modo de intervención en la construcción de significado en la identidad americana, actuando sobre el pasado y el futuro y buscando un lugar en el concierto internacional (Rodríguez, 2018).

Más allá de las intenciones, la propuesta americanista de enseñanza de la historia no logró concretarse en tanto ningún país procuró implementar realmente las propuestas. Posiblemente, las razones de esta situación se relacionaban con la denominada "teoría del garrote", impulsada en Estados Unidos por el presidente Theodore Roosevelt (1904-1908) y continuada hasta los primeros años de la década del 20. Se trataba de una política intervencionista sobre las naciones latinoamericanas, siendo especialmente afectadas las regiones de Centroamérica y el Caribe (Halperín Donghi: 1998, 321-323). Discutir sobre la historia y su enseñanza obligaba a considerar las tensiones existentes entre los países del continente americano. La presidencia de Franklin D. Roosevelt (1932-1945) propició un cambio que había comenzado a gestarse entre los años 30 y la segunda guerra mundial. La política de la "buena vecindad" procuraba disminuir conflictos y EEUU renunciaba así a la intervención armada directa (Halperín Donghi, 1998, p. 407).

Desde el final de la Segunda Guerra Mundial, en particular desde 1960 emerge un nuevo marco político internacional cuyo rasgo sobresaliente estará representado por el conflicto este-oeste y el contexto de la Guerra Fría. Las cuestiones relacionadas con la educación, los saberes y la ciencia ocuparán un rol innovador dentro de las políticas públicas de los Estados. Es por esto que las relaciones entre estado y ciencia se modifican, en interacción directa con la industria y la sociedad. En las gestiones de proyectos prioritarios de investigación se nota la presencia cada vez mayor de científicos y expertos que definen conjuntamente con el Estado las políticas en ciencia y tecnología (M. Medina y J. Sanmartín, 1990; Dowker G., 1991; Saldaña, J.J., 1996; Hobsbawm E., 1999; Solís C. y Sellés M., 2005; Riquelme, G., 2008)

En este contexto, la historia de América Latina presentaba un importante desarrollo, al punto de llegar a conformar una subdisciplina, relativamente joven, dentro del campo de los estudios históricos (Pietschmann, 2000, pp. 23-49). La emergencia de este campo de investigación debe leerse en la clave indicada. América Latina fue interpretada como una zona de influencia directa de Estados Unidos o como un campo de enfrentamiento entre las grandes potencias. Tomada como un todo, pronto se disiparon sus peculiaridades y problemáticas, apareciendo como una de las regiones del mundo más disputada por las potencias internacionales en conexión con los intereses de las propias élites latinoamericanas. La Historia de América Latina aparece en Estados Unidos, en Europa, en el Japón y en Alemania (Sauro, 2018, mimeo). ${ }^{1}$ Más específicamente, se trata de campos de estudios de docencia e investigación que encuentran cierta resistencia en las antiguas instituciones del quehacer historiográfico que reconocen desde su eurocentrismo decimonónico, cierto exotismo en el estudio de América Latina, sumado a lo extraño y lejano; a diferencia 
de la política, la diplomacia y los agregados culturales que encuentran en el estudio y la investigación de Latinoamérica una puerta de entrada complementaria para sus planes políticos.

En este marco Argentina atravesaba un proceso de intensos cambios que se venían arrastrando desde el golpe del 55 y terminan por sobrepasar la década de los años 60. Por un lado, la búsqueda de un modelo de desarrollo superador del peronista populista y la instauración de un régimen democrático con proscripción del peronismo. Por el otro, el aumento demográfico y de la conflictividad social, así como la aparición de una cultura juvenil de impronta rebelde. Por lo tanto, la Argentina de los 60 mantenía su base tradicional en tensión con las ideas que intentaban modernizarla, se mostraría predominantemente liberal en lo económico, conservadora en lo político y reaccionaria en lo cultural (Tcach, 2007).

El reiterado círculo vicioso entre golpes militares y gobiernos civiles débiles, no sólo produjo que los partidos políticos perdieran legitimidad sino que puso en cuestión la propia noción de democracia hasta convertirla en un desvalor. Confrontaciones políticas varias y formas ilegítimas de acción operarán sobre ella durante las décadas del post peronismo, el retorno y la resistencia.

Los parámetros del nuevo sistema internacional influyeron en la redefinición de los planes económicos. La reorientación de los vínculos entre capital y trabajo afectó la distribución de la renta nacional. Las tensiones generadas por los intentos de promover cambios en el modelo económico, en la distribución del ingreso y en los desarrollos regionales dieron lugar al surgimiento de nuevos actores sociales, que respondieron acomodándose o resistiendo. Esta etapa de la historia argentina está signada por las tensiones sobre las que se debaten los contenidos, criterios y alcances de la organización de una nación moderna.

La experiencia de la Revolución Cubana y los diferentes procesos de liberación nacional promovieron nuevas formas de accionar político desde "la lucha armada y "la liberación nacional" hasta "la guerra de guerrillas", pasando por el "hombre nuevo".

La sociedad argentina en su conjunto sufre un intenso proceso de transformación resultando clave el debate político ideológico en el seno de las instituciones universitarias.

En este clima de agitación social y confrontación ideológica, las fuerzas armadas comenzarán a asumir el control social interno. Las huelgas obreras de extracción sindical peronista serán reprimidas junto con la proscripción del PC (Partido Comunista) y la persecución ideológica de las ideas comunistas. Desde 1959, el Plan Conintes fue aplicado para encarcelar a los militantes de izquierda y a la resistencia peronista. La idea de "guerra" en las Fuerzas Armadas se trasladaba del ámbito internacional de la Guerra Fría al ámbito interno. Esta situación derivó en la militarización de la política por la presión ejercida hacia el presidente, y una politización de la institución militar que llevó al propio fraccionamiento de los grupos denominados azules y colorados. Legalistas los primeros, aceptaban el sometimiento al poder civil, anti-integracionistas los segundos, priorizaban la lucha antiperonista. La lucha culmina con el nombramiento del general Onganía como comandante en jefe del Ejército y de Rodolfo Martínez en el Ministerio del Interior. Se intentaba la subordinación del peronismo y la formación de un frente político más amplio que lo incluyera. De este modo, se integraba el peronismo a la política pero no retenía todo el poder en sus manos. Se pensaba en que Onganía podía ser el candidato "ideal" a presidente de la República. Se acordó con dirigentes peronistas (Iturbe y Vandor) a través de la Unión Popular (UP) en 1963, pese a las reticencias de la Marina. Por su parte, el comité nacional del radicalismo apoyó a los militares derrotados y llevó a la candidatura a Arturo Illía bajo el lema "Por la Civilidad y la Democracia". La campaña se realizó en medio de varios intentos golpistas y nuevas proscripciones al peronismo. A penas con el $25 \%$ de los votos por sistema de representación proporcional, Illía llega a la presidencia en 1963. Radical de base sabattinista, formó parte de los radicales que se enfrentaron al conservadurismo en la década del 30 y el peronismo después, pasó por cargos políticos de senador provincial, vicegobernador de Córdoba, diputado nacional por esa provincia bajo el peronismo y gobernador en 1962. De tradición yrigoyenista y reacio a las alianzas políticas, formó su gabinete con figuras del partido a diferencia de Frondizi. Intentó un gobierno de partido y no de técnicos, y gobierno de un solo partido. Como ejemplo valga la anulación de los contratos petroleros por decreto como signo ideológico de defensa de la soberanía 
nacional. Su política económica fue criticada por la Unión Industrial al basarse en el intervencionismo y el keynesianismo estatales, centrados en la distribución y en el mercado interno, por influencia de la CEPAL (Comisión Económica para América Latina) que favorece una nueva inserción de la periferia en la división internacional del trabajo.

Mantuvo al general Onganía como comandante en jefe del Ejército y a los integrantes de la Corte Suprema de Justicia. También con la Iglesia mantuvo cautela al eximirlos del juramento de acatamiento a la Constitución Nacional al asumir el gobierno de las diócesis y arquidiócesis, obligación que databa del año 1879.

La relación del gobierno con los sindicatos resultó problemática al intentar modificar la Ley de Asociaciones Profesionales para romper el monolitismo peronista en los sindicatos. La respuesta de fue un duro plan de lucha.

El llamado "Operativo Tortugas" que pretendía marcar la lentitud del gobierno para actuar en los conflictos obrero-patronales, ponía en juego el problema de fondo de la modernización de la Argentina. La lectura periodística y de opinión pública vinculaba la lentitud con la ineficacia jugándose así un intento desestabilizador. La visita del presidente francés Charles de Gaulle detonó en la "operación retorno" alentada por Vandor. El gobierno radical impide el regreso de Perón a través de una maniobra diplomática. A partir de esto, los conflictos fuera y dentro del peronismo reaparecen con mayor virulencia.

En el contexto cultural y de opinión pública circulaba la idea de la caducidad e ineficiencia del sistema de partidos que llevaba a la demagogia y frenaba la modernización. Asimismo, la modernización exigía suprimir al "Parlamento", encerrado en una retórica caduca y populista. Esta campaña desestabilizadora desde lo civil se correlacionaba con el accionar de las fuerzas armadas anti partidistas y antiperonistas. La política debía sustituirse por la administración.

En el ámbito internacional cabe destacarse en 1964 la firma con Estados Unidos del denominado "Memorándum de entendimiento" relativo a la cooperación militar entre ambos gobiernos. El objetivo era combatir la amenaza comunista-castrista que intentaba infiltrarse en los países latinoamericanos. Estados Unidos ponía a disposición militares, equipos y servicios. Meses después, en la V Conferencia de Ejércitos Americanos realizada en West Point, Onganía expresa su opinión respecto de los golpes militares: pasarían a ser legítimos en el caso de que los gobiernos electos usaran sus prerrogativas constitucionales para desvirtuar los valores occidentales y cristianos. La teoría de las fronteras ideológicas y la noción de "guerra interna" se afianzaban cada vez más entre los militares argentinos. A la inicial influencia francesa, fruto de su experiencia en Argelia, sucedió la proyectada desde los Estados Unidos.

El golpe del 28 de junio de 1966 había sido reiteradamente anunciado. El derrocamiento de Illía por los comandantes en Jefe de las Fuerzas Armadas inicia la dictadura de la Revolución Argentina. Destituyeron al presidente, al Parlamentó, a la Corte Suprema de Justicia y disolvieron todos los partidos políticos. $\mathrm{Al}$ asumir la presidencia, el teniente general (RE) Juan Carlos Onganía juró "observar fielmente los fines revolucionarios, el Estatuto de la Revolución y la Constitución de la Nación Argentina". En la novedosa fórmula el Estatuto reemplazaba a la Constitución, legitimándose en su artículo 1 su propia designación por los militares golpistas. Al mismo tiempo, los "fines revolucionarios" debían entenderse como la consolidación de "los valores espirituales y morales" (...) "patrimonio de la civilización occidental y cristiana". La nueva relación empresarios-obreros se expresaba en el deseo de "alcanzar adecuadas relaciones laborales".

Onganía ponía de manifiesto una visión paternalista y corporativista de la política que lo emparentaba con el universo ideológico de Francisco Franco, otros, como el general Julio Alsogaray (hermano de Álvaro, flamante embajador en los Estados Unidos), se identificaban con una postura presuntamente liberal pero carente de fe en las instituciones republicanas y en las libertades individuales.

Las organizaciones burguesas respaldaron de inmediato al nuevo presidente. Lo mismo hizo gran parte de la prensa, empeñada en justificar la ruptura del orden institucional en virtud del "vacío de poder". Su fascinación por la técnica y la eficacia, constituían elementos clave para la modernización autoritaria del país. 
Por consiguiente, los "técnicos" fueron percibidos como la encarnación misma de la racionalidad económica y operaron como punto de confluencia entre estado, gran burguesía y capital transnacional.

En el plano cultural y educativo, el gobierno procedió interviniendo las universidades nacionales para limpiarlas de toda ideología marxista y las ubicó en la jurisdicción del Ministerio del Interior. El hecho más significativo de esta política es la conocida como "Noche de los Bastones Largos" que terminó con la renuncia en masa de parte de su cuerpo docente. Su lugar fue ocupado por sectores clericales y conservadores.

\section{ConteXto de la CARrera de Historia entre 1955/66}

El período del peronismo no había generado cambios importantes en la orientación de los estudios de historia, siendo hegemónica antes y después del 55 la tradición de la Nueva Escuela Histórica y su forma de practicar la investigación histórica. El 55 trajo la reincorporación de Caillet Bois al Instituto de Investigaciones Históricas. Las cátedras de Historia Argentina y Americana mantenía la misma línea de estudio centradas en el enfoque de la historia política e institucional.

Desde finales de los años 50 parece identificarse la existencia de otros historiadores profesionales que van a cuestionar a los nucleados en la NEH por su forma de practicar el oficio. Al interior de la carrera de Historia conviven estos dos sectores, tradicionales unos y renovadores los otros, entre los que podría advertirse cierta tensión latente. Al mismo tiempo, se desarrollaba el proyecto renovador en la Universidad de Buenos Aires con Romero como Rector. A nivel de la carrera de Historia la renovación proponía nuevas formas de hacer historia basadas en los problemas del presente como hilo conductor hacia el pasado, un enfoque desde la historia de la cultura recalara en la historia social y ampliara la problematización político-institucional. El nuevo plan de estudios que se aprueba para la carrera en 1959, en algún sentido, pone de manifiesto estas dos perspectivas.

En verdad, el nuevo plan no presentó grandes cambios. Lo sustancial aparecía en la división entre ciclos y orientaciones, y en la introducción de dos nuevas asignaturas, Historia Social y Teoría e Historia de la Historiografía ${ }^{2}$. El sector renovador, de la mano de Germani y Romero, propició la actualización del curriculum e impactó en la formación de la historia social y de los seminarios de orientación con perfil interdisciplinario entre historiadores y demás ciencias sociales. Los procesos históricos fueron abordados desde el análisis económico y social.

En el campo historiográfico NEH va a mantener el control del área de las historias argentinas y latinoamericanas, así como la dirección del Instituto de Investigaciones Históricas, la organización de eventos y congresos internacionales, el manejo institucional de patrimonio ${ }^{3}$. Su campo de acción estará representado por la historia tradicional y las humanidades con perfil hispanista. Realiza los Congresos Internacionales de Historia de América entre 1961 y 1966 (Rodríguez, 2016). Entre sus referentes internacionales y visitantes al país, puede mencionarse a A. Toynbee, contrario a los fundamentos de la renovación historiográfica de los años 60. También va a monopolizar la historia norteamericana especialista en Latinoamérica (Scobie, por ejemplo) o anglosajona (Lynch, por ejemplo) y los congresos hispanoamericanistas.

Pese a que en los años 60 el campo historiográfico internacional se había renovado y en el ámbito local también se intentaba una transformación, la producción historiográfica de NHE seguía sujeta a una práctica que para ese contexto resultaba doblemente arcaica. Sin embargo, frente a su modo de vinculación con los poderes públicos, este tradicionalismo metodológico no significaba ninguna debilidad. Muy por el contrario, era su fortaleza, se reconocía en ella el saber legítimo y científico, erudito y objetivo despojado de toda ideología o partidismo que el poder de turno asumía en su representación histórica del pasado. Tampoco perdía reconocimiento dentro de la red de historiadores internacionales gestada desde Levene y Ravignani que seguía practicando el oficio según cánones más tradicionales.

Considerado el aporte del sector renovador al campo local de la historia, el balance final de este grupo pone más en evidencia su debilidad que su fortaleza. Justamente, con el episodio de la Noche de los 
Bastones Largos puede ilustrase tal valoración; asimismo comprenderse el final de un proceso iniciado con la modernización de la universidad y la defensa de su autonomía. El golpe de Onganía y la intervención policial a la universidad fueron apoyados por los sectores más conservadores de la clase dominante, incluyendo profesores y autoridades universitarias. En el aspecto político, la $\mathrm{NEH}$ va a resultar permeable a los cambios políticos e institucionales. De hecho, mantuvo vínculos con el radicalismo, el frondizismo, y el ongianato. Por su lado, el sector de los renovadores va a desarmarse luego del golpe del 66. El campo de la historia social y económica se vio afectado directamente por la renuncia de algunos profesores o el exilio de otros. En consecuencia, el terreno historiográfico e institucional volvió a quedar completamente en manos del academicismo de la NEH.

En el aspecto geopolítico, el Golpe militar de Onganía, y por ende, la Noche de los Bastones Largos significaron un ataque a toda ideología que fuera en contra de la concentración capitalista y pudiera atentar contra la seguridad nacional. Estos objetivos se articulaban, en forma explícita y directa, con los intereses de la política exterior de Estados Unidos en la Guerra Fría.

\section{Jornadas y Plan de Estudio, entre Illía y Onganía}

En 1965 dos acontecimientos resultan disruptivos en el campo historiográfico con relación a la presencia de cursos y jornadas que vinculan la Historia Argentina y la Historia Americana. En primer lugar, Las Jornadas de Métodos de Investigación de la Enseñanza de la Historia y de la Literatura Rioplatense y de los Estados Unidos. En segundo lugar, la aprobación del Plan de Estudios de la Carrera de Historia con Especialización en Historia Argentina y Americana. Ambos serán gestionados desde NEH arrancando antes del Golpe de 1966 y continuando después de ocurrido.

Una carta de diciembre de 1965 enviada por el Director del Departamento de Historia (Luis Arocena) al Director del Instituto de Historia Argentina y Americana (Ricardo Caillet-Bois) ${ }^{4}$ le informa que para el siguiente año se proyecta el dictado de dos seminarios que responden a exigencias del plan de estudios vigente. Uno de ellos "Metodología y técnicas de Investigación en Historia Americana y Argentina (Historia de Estados Unidos)" (sic.). El Plan aludido había sido discutido durante el mes de diciembre y aprobado a finales de dicho mes, entre los días 28 y 29 (Resolución C/D 4040). Julio C. González, quien fuera también director del Archivo General de la Nación, participó como consejero y orador en la sesión de Consejo Directivo. En el Ciclo de Orientación aparecían Historia social y económica de la Argentina; Historia de América Anglosajona; Historia social y económica de América Latina. Entre los Seminarios de Especialización se ofertaban dos grupos. Uno con 5 para elegir 4: Historia Argentina; Historia Americana; Historia de las Ideas; Sociedad y Economía (Argentina y Americana) Historia Política Internacional (Argentina y Americana). Otro de 2 para elegir 1: Metodología y técnicas de Investigación (Argentina y Americana) y Metodología y técnicas de Investigación (Sociedad y Economía)

El grupo erudito conservaba el área de las argentinas y americanas con orientación institucional y política, el seminario de metodología y técnicas investigativas argentina y americana. Conjuntamente, la correspondencia institucional y las publicaciones del Boletín del Instituto de Investigaciones Históricas de la FFyL desde 1966 en adelante, se puede leer la presencia del grupo erudito organizando las Jornadas y, como antecedente, gestionando los seminarios y cursos en la Carrera de Historia de la FFyL-UBA.

Las cartas indican los avances en las tratativas para la realización de las primeras jornada, destacan la colaboración del Profesor Roland T. Ely y de la Comisión Fullbright. ${ }^{6}$ El temario destaca el estudio de las tesis de frontera y su aplicabilidad en la historia argentina; la influencia del pensamiento constitucional norteamericano en el Río de la Plata; la necesidad de relacionar la historia de América; la actualización de las investigaciones históricas y su aplicabilidad en la enseñanza secundaria y primaria. Otra carta de mayo de 
1966 se refiere a la solicitud para obtener la colaboración de un profesor de Historia de los Estados Unidos para el año académico 1967.7

Entre 1966 y 1971 tiene lugar la realización de las 6 jornadas. Las cinco primeras, organizadas por el Instituto de Historia Argentina y Americana y el Instituto de Literatura Argentina en forma conjunta, tuvieron como sede diferentes universidades del país. La VI a pesar de haber sido organizada por la Asociación de Estudios Americanos, mantiene en la presidencia a los directores de los Institutos organizadores de las cinco primeras (Ricardo Caillet-Bois y Delfín Garasa, respectivamente). En el Boletín del Instituto Ravignani se publican los comentarios y las actas.

La primera acontece del 1 al 3 de agosto de 1966, sin que se perciba ningún tipo de inconveniente manifiesto. Recordamos que para ese entonces no sólo había ocurrido el Golpe de Onganía (28 de junio) sino la intervención a la Universidad de Buenos Aires, acontecimiento conocido como la Noche de los Bastones Largos (28 de julio).

La continuidad de estos encuentros académicos, el dictado de los cursos, más la oferta de becas y los cambios geopolíticos, contribuye a explicar la introducción y consolidación de los estudios de la historia de Estados Unidos en las universidades argentinas.

A continuación, se analizará en detalle un trabajo del profesor Roland T. Ely que fuera presentado en las Primeras Jornadas.

\section{La Ponencia del Profesor Roland T. Ely: "Una buena cerca no hace buenos VECINOS"}

Si bien esta ponencia fue presentada en las Primeras Jornadas ocurridas en Buenos Aires en agosto de 1966, se publica en el Boletín del Instituto en 1969 (p. 182-201). El Profesor Roland Ely expone su trabajo en dos partes. I- Necesidad de relacionar la historia de las América ("buenos vecinos"); II- Enfoque pragmático del problema metodológico con el título, "Una buena cerca no hace buenos vecinos", pretende resaltar la necesidad de estudiar las historias de las nuevas naciones sosteniendo que las "cercas intelectuales" no ayudan a forjar buenos relaciones. Sino que la mejor manera de conocerse es a través del estudio de las respectivas historias de las naciones "No hay armas mejores para combatir los prejuicios" Indica además que Estados Unidos ha fundado muchísimas cátedras de estudios de historia latinoamericana en diversas universidades. Destaca asimismo que espera que el ejemplo que se está desarrollando en la Facultad de Filosofía y Letras de la UBA con respecto a los estudios norteamericanos, se multiplique por otras universidades argentinas.

Comenta la experiencia en la UBA. Indica que entre abril de 1965 y julio de 1966 se han sentado las bases en el dictado de materias, seminarios temáticos y de investigación, metodología e historiografía. Asimismo, señala que llegó la hora de consolidar un programa de becas para estudiantes sobresalientes que quisieran realizar doctorados y maestrías en EEUU. Se intentaba una estrategia de intercambio, procurando que con el tiempo los profesores argentinos dictaran historia norteamericana y los profesores norteamericanos historia argentina y latinoamericana. Conjuntamente con los cursos de formación, debía crearse un campo de investigación para complementar la docencia y las publicaciones; apoyarse la producción de materiales para docentes de enseñanza secundaria y de folletos especializados para actualización docente en historia argentina y americana.

Los profesores argentinos que vuelvan al país con títulos de Doctores o Magísteres de Universidades de EEUU podrán insertarse en el Departamento de Historia y en el Instituto de Investigaciones de la FFyLUBA. El objetivo es ampliar el área y el período de estudio de temas latinoamericanos y EEUU.

En el apartado de su ponencia, "Enfoque pragmático del problema metodológico", desarrolla con sumo detalle el contenido de los cursos y seminarios. Se refiere a las lecturas introductorias, cursos panorámicos, trabajos prácticos, cursos de historiografía contemplando análisis e interpretaciones antagónicas y seminarios relacionados con temas de Historia de EEUU y sus vínculos con América Latina, enfatizando en el problema 
de cómo llega EEUU a convertirse en una superpotencia mundial. A continuación me referiré a cada uno de estos puntos.

1- En este apartado, Lecturas de introducción, cita la bibliografía de los cursos dictados, concretamente, dos textos y aclara que han sido donados al Instituto Ravignani por la Biblioteca Lincoln: Síntesis de la historia de Estados Unidos, por Whitney, Libreros Mexicanos Unidos, 1964; y Los Estados Unidos en el siglo XX (T I y II) por Frank Freidel, Novaro, México, de la Universidad de Harvard. La exclusiva selección de estos materiales, aclaró Ely, se debió al interés de brindarles a los estudiantes conocimientos generales introductorios. Si bien el primer curso llega hasta 1877, la lectura de Freidel busca entusiasmar a los alumnos para conocer el pasado conociendo algo del presente de los Estados Unidos (p. 191)

2- El curso panorámico de estudio: abril a diciembre de 1965

Este curso tiene por objetivo ofrecer el marco histórico y familiarizar a los alumnos con los sucesos históricos para abordar los problemas de cómo y porqué sucedió. Partiendo de los acontecimientos se intenta llegar al análisis, la síntesis y la interpretación. Se busca ejercitar a los alumnos en la mirada crítica, valorar y diferenciar los hechos de mayor y menor importancia; encontrar relaciones, interrelaciones y síntesis, buscar significados y posibles implicancias en la época actual (p. 192). Por lo tanto, las nuevas metodologías que aquí aparecen atienden fundamentalmente al estudio de "los problemas de causación histórica, esto es el proceso analítico del pensamiento histórico" (p. 192)

3- Lecturas obligatorias y conferencias

La selección bibliográfica resultó problemática debido al problema de las traducciones, ausencia o escasez de ediciones castellanas de las obras norteamericanas clásicas, algunas incluso están agotadas o son muy costosas. Se optó por Nueva Historia de los Estados Unidos de William Miller, Nova, Buenos Aires, 1961. Este material era de "fácil lectura" y de "interpretación brillante" y se encontraba en la librerías de Buenos Aires (p. 192/193) Como lecturas adicionales, se recomendaron los dos volúmenes de The American Past: Confliction Interpretations of the Great Issues, editado por Sidney Fine y Gerald S. Browmn, Macmillen, Nueva York, 1961 y 1965, segunda edición; A History of the United States (tomos I y II) de T. Harry Williams, Richard N. Current y Frank Freidel, Knoff, Nueva York, 1964.

Para dar una síntesis concisa del material de lectura de los cursos panorámicos se dictaron conferencias semanales. En el caso del primer curso, Los Estados Unidos hasta 1877, abril de 1965, los tópicos fundamentales que se tocaron fueron: 1) Expansión de Europa Occidental; 2) Aparición de los ingleses; 3) Panorama social de América anglosajona; 4) Problemas de fiscalización imperial; 5) La lucha anglofrancesa por la supremacía; 6) Conflicto de intereses en el Imperio; 7) Revolución en lo político y en lo social; 8) El establecimiento de la nueva nación; 9) El régimen federalista; 10) Los jeffersinianos; 11) Espíritu nacional en ascenso; 12) La democracia jacksoniana; 13) Los frutos del "Destino Manifiesto"; 14) La sociedad norteamericana hace un siglo; 15) Esclavitud y regionalismo; 16) La guerra que unificó a la nación; 17) Construyendo una nueva nación.

En el segundo curso, agosto a diciembre de 1965, los principales temas tratados fueron: 1) Un sistema económico en expansión; 2) Atolladero en política; 3) Empresa privada vs. Intervencionismo; 4) El "status" del obrero; 5) El oeste en rebelión; 6) El camino hacia el Imperio; 7) La era de Teodoro Roosevelt; 8) El liberalismo wilsoniano; 9) La Primera Guerra Mundial; 10) Perspectivas de prosperidad nacional; 11) La crisis económica y el "Nuevo Tratado" de Franklin Roosevelt; 12) El impacto del poder mundial; 13) La Segunda Guerra Mundial; 14) En busca de la paz y seguridad. La elección de Lyndon Johonson y los problemas internos e internacionales de los Estados Unidos en 1965.

4- Trabajos prácticos

Con el objetivo de que los alumnos pudieran realizar estos trabajos se le envía semanalmente memorándums con modelos de preguntas típicas de exámenes orales y escritos y temas a desarrollar. Al mismo tiempo, se intenta que ciertas problemáticas puedan someterse a debate y discusión. En las páginas 194 a 196 se desarrollan este tipo de consignas, preguntas modelo de parcial escrito y de examen oral. 
5- Curso en la historiografía antagónica, abril a julio de 1966

Se dictó un curso, Momentos decisivos de la historiografía norteamericana, con el objetivo de adiestrar a los alumnos en la historiografía antagónica a través de especialistas en cada uno de los temas tratados El núcleo de la lectura obligatoria se basó en los dos tomos de Freire y Brown. Pero en verdad, los alumnos utilizaron los manuales preparados con las traducciones de los resúmenes del texto completo.

El curso trató acerca de seis cuestiones generales en la historia de Estados Unidos. En cada uno se buscó enfocar el tema problematizándolo para lograr un pensamiento más flexible y profundizar el estudio del pasado norteamericano sobre la base del primer curso que había ofrecido una visión más panorámica. Se presentaban, por lo tanto, perspectivas antagónicas para estimular la capacidad crítica de los alumnos. En segundo término, se ofrecía un material bibliográfico que de otro modo, hubiera resultado inaccesible para el estudiante latinoamericano corriente. Estos materiales reunían un conjunto de trabajos publicados en revistas históricas, publicaciones especializadas y monografías de investigaciones realizadas en los estados Unidos. El alumno recibía una información versátil, invitaba al debate y daba cuenta de lo producido y existente en las bibliotecas de las grandes universidades norteamericanas. Así se podría, además, valorar la rica y diversa historiografía norteamericana contemporánea.

A modo de ejemplo. El ítem "La revolución norteamericana" se abordaba con su enfoque problemático planteando la pregunta: Democracia en Norteamérica colonia, ¿realidad o ficción?

La cuestión "Los artículos de la Confederación” se interpelaba con la pregunta ¿Determinismo económico o teoría política del siglo XVIII? El problema de las fronteras nacionales, entendido como un "Destino Manifiesto", se encaraba desde la pregunta/problema: en 1846, esto resultaba mística o extensión del área de libertad.

6- Seminario, abril de 1965 a julio de 1966

Adiestrar a los alumnos en metodología y técnicas de investigación para el estudio de la historia norteamericana en sus aspectos económicos y sociales desde 1865. La lectura en este caso resultó ser la Historia económica de los Estados Unidos de Harold U. Faulkner, Nova, Buenos Aires, 1956.

Las lecturas se coordinaban con debates y charlas con instructores sobre los problemas económicos y sociales desde el final de la Guerra Civil, tocándose los problemas de la desaparición de la frontera; el progreso y la crisis de la agricultura; la revolución industrial; inmigración y racismo; imperialismo económico, entre otros.

La modalidad de trabajo era la típica de seminario, redacción final de un trabajo de investigación, entregas parciales de avances para exponer y discutir con el instructor y el resto de los alumnos, redacción de borradores y corrección para entregar. Formato. Notas a pie, bibliografía. Defensa en un coloquio en el cual se debería mostrar el grado de articulación que el trabajo tenía con las lecturas y las clases del curso.

Luego de desarrollar las partes I y II el Profesor Ely comenta que lo expuesto debe ser tomado como la opinión personal basada en la experiencia de un individuo que quiere compartirla para aportar, o al menos, despertar interés en la introducción de la Historia de los EEUU en los Programas oficiales de las Universidades Latinoamericanas. Sobre la base permanente de la idea de "buenos vecinos", continua comentando, se logrará construir y promover el entendimiento interamericano, los círculos diplomáticos y políticos. Lo mismo está ocurriendo con la enseñanza de la historia y de la lengua de EEUU en la Unión Soviética ya que ambos deben respetarse mutuamente, aunque no lleguen nunca a ser "vecinos excesivamente cordiales". Por el contrario, se espera que los alumnos o estudiantes inteligentes de América Latina asuman el deber consigo mismo de llegar a un mejor conocimiento del "Coloso del Norte", de su historia y de sus instituciones. Fin del comentario de Ely. 


\section{Pasando revista a las jornadas, PONEnCias y PONENTES}

Como primer comentario, estamos en condiciones de indicar que todos los trabajos presentados a lo largo de las seis jornadas muestran por un lado su directa correlación con los contenidos de los cursos y seminario del Programa de Intercambio Educativo diseñado por la Fundación Fullbright; y por otro lado, aparecen en absoluta sintonía con la parte II de la ponencia del Profesor Ely expuesta anteriormente.

A continuación se fundamentará esta idea sobre la base de la presentación detallada de las jornadas según el registro de las Actas publicadas en el Boletín del Instituto Ravignani, o de documentos pertenecientes a su Archivo Documental.

Los seis temas de la Primera Jornada ${ }^{8}$ aparecían en estrecha relación con los contenidos de los cursos: tesis de frontera y su aplicabilidad a la historia Argentina; influencia del pensamiento constitucional norteamericana en el Río de la Plata; relación de la historia de América; relación entre las investigaciones históricas y su aplicabilidad a la enseñanza primaria y secundaria; importancia de los hechos económicos en las relaciones de Estados Unidos con el Río de la Plata, 1865-1890; los corsarios rioplatenses y los Estados Unidos.

La segunda Jornada se realiza en Buenos Aires, en el Ex Concejo Deliberante en noviembre de 1967. En esta oportunidad, el eje temático resultó ser "Búsqueda del ser nacional (1810-1940)”. Al igual que las primeras, contaron con el auspicio y colaboración de la Comisión de Intercambio Educativo entre los Estados Unidos y la Argentina (Comisión Fullbright). Las palabras de bienvenida estuvieron a cargo de su Presidente, Philip Conley y el Presidente de la Comisión de Historia, Profesor R. Caillet Bois.

Las presentaciones se encuentran en una nota publicada en el Boletín del Instituto Ravignani. ${ }^{9}$ Docentes, investigadores y auxiliares del Instituto han contribuido con sus trabajos. Se mencionan, entre otros, los aportes de Hebe Clemente (relatora de la Comisión y Secretaria de Redacción del Boletín del Instituto), "El mito agrario en el ser nacional norteamericano"; de Roberto Etchepareborda, "El ser nacional"; de A. J. Pérez Amuchástegui, "Búsqueda del ser nacional, 1810-1940”, y de German O. E. Tjarks, "Etapas críticas en la búsqueda del ser nacional en el Río de la Plata, 1810-1880".

Sin indicar procedencia institucional, se registra el trabajo del profesor Félix Weinberg “:Exotismo o universalidad? El ser nacional y las ideas exógenas", y el de Leandro Gutiérrez, "El incendio del colegio del Salvador, 1875, expresión de protesta social".

La nota comentada no tiene firma pero se indica que en todos los casos la lectura de los trabajos suscitó discusión para marcar diferencias y similitudes y resaltar los nuevos enfoques.

Las Terceras Jornadas se organizaron en la ciudad de Mendoza en 1968 pero hasta donde pudimos rastrear, no se registra nota o comentario en el Boletín del Instituto.

Las Cuartas Jornadas se realizaron en la ciudad de Bahía Blanca, con la cooperación de la Universidad Nacional del Sur junta al resto de las instituciones que venían organizando las jornadas anteriores. Esta vez se propuso como eje central "Temas conflictos de historia y literatura de la Argentina y de los Estados Unidos en el período 1900-1930”. La Comisión de Historia estuvo presidida por Roberto Etchepareborda y con Caillet Bois y Julio C. González en la vicepresidencia.

Un total de veinte ponencias y variados temas, algunas en co-autorías, despertaron interesantes debates y mostraron temas y enfoques novedosos, según el comentario de Caillet Bois, autor de la nota aparecida en el Boletín. ${ }^{10}$ En su comentario final, el Director del Instituto elogia el trabajo en equipo y las contribuciones de alumnos y graduados de la Universidad del Sur y de la de Buenos Aires "que dieron un ejemplo indiscutible de cómo la coordinación y unidad de método, permiten realizar un considerable progreso”

Las V Jornadas se realizaron en la ciudad de Carlos Paz en 1970, siendo sede y organizando la Universidad de Córdoba, con el Profesor Segretti a la cabeza y la colaboración de Garasa, Caillet Bois y Pedro David 
(Comisión de Intercambio Educativo). El tema convocante fue esta vez, "Situaciones conflictivas entre la República Argentina y los Estados Unidos entre 1890 y 1940". ${ }^{11}$

Hebe Clementi y Caillet Bois, Director y Secretaria del Instituto organizador de las Jornadas acompañan la publicación del acta de las $\mathrm{V}$ Jornadas con un comentario en el que destacan los importantes logros obtenidos. Indican el aumento del número de estudiantes y egresados de universidades argentinas, los profesores universitarios estadounidenses y la cantidad y calidad de los trabajos presentados en cada jornada. Asimismo, se menciona y se reconoce elogiosamente al Prof. Ely por la iniciativa que condujo a la realización de las Primeras Jornadas. También destacan la formación de tesistas y ponentes bajo su dirección. Todos estos datos ponen en evidencia la consolidación de la línea de investigación que vincula la historia norteamericana y la historia argentina. Hasta aquí el comentario de las autoridades del instituto.

Comparada con el resto, el acta de la V Jornada resulta ser la detallada. Aparece el título de la ponencia, un breve comentario sobre su contenido, su autor/a y su la referencia institucional. E incluso, se indica si ha realizado el o los cursos con el Profesor Ely. Así podemos saber quiénes fueron los alumnos, provenientes en su totalidad de las Universidades de Buenos Aires (Norma Asato; Marta Lauría; María Inés Soulés; Olga Gracía de D 'Agostino) de La Plata (Marcelo Sarrasqueta; Samuel Amaral) y de El Salvador (Prof. Carol Ordoñez).

El acta de la VI jornada vuelve a ser una descripción somera, informativa y sin mayores comentarios. ${ }^{12}$

Profesores norteamericanos también presentaron sus trabajos. Entre ellos, el propio Ely y Tulchin (Universidad de Yale), Francis Bethlen (Universidad de Nueva York, profesor visitante en Universidad de Córdoba).

Otro grupo de ponentes provenía de la Universidad del Sur (Guillermo Godio; Norma Abraham, Delia Errazu, María Rey; Hernán Asdrúbal Silva).

Sin indicar procedencia Ofelia Pianetto y Aníbal Arcondo aparecen como ponentes.

Otros ocho autores dirigidos por el Profesor Segretti aportan temas diversos, fuentes inéditas y bibliografía específica para abordar temas socioeconómicos, con fuerte trabajo empírico de fuentes y abren trabajos de largo aliento.

La lectura de estas fuentes indica que los trabajos presentados rondan los 30, resultando la jornada más numerosa en cuanto a recepción de trabajos. Esta jornada también se diferencia de las otras en cuanto a los temas de los trabajos, presentando una mayor diversidad con respecto a las líneas del programa de Ely. Vemos así el surgimiento de trabajos y autores que atienden a problemáticas puntuales, locales y con perspectivas que suponen formación en ciencias sociales, sociología y la economía, especialmente. Pongo algunos ejemplos: "Los comienzos del movimiento obrero en Bahía Blanca", ponencia presentada por las profesoras Norma Beatriz Abraham, Delia Errazu y María E. Rey que toma las huelgas de 1902 y 1907, y constituye un aporte a la historia social y provincial. Otro: "Santa Cruz, 1921-1922, condiciones para un alzamiento", ponencia de Hernán Asdrúbal Silva y Rosario Guenega de Silva, aborda el contexto histórico para el estudio del movimiento obrero patagónico. Utiliza fuentes militares de los represores e informes de la delegación norteamericana en la Argentina. Resulta muy enriquecedor por el tratamiento de las fuentes. Postula el aislamiento de la zona, la falta de conciencia nacional, los problemas de soberanía y la composición de la población nativa y extranjera. Un tercer ejemplo sería el trabajo de Ofelia Pianetto y Aníbal Arcondo, "La evolución de la industria molinera argentina y el mercado de harinas de Brasil" constituye un estudio de historia económica que vincula Argentina y estados Unidos entre 1880 y 1914. El análisis combina industria, relaciones diplomáticas y comerciales y política nacional e internacional. Finalmente, un cuarto ejemplo sería el trabajo de Samuel Amaral que analiza los componentes teóricos que confluyen en la estructuración del capitalismo de empresa norteamericano para configurar su originalidad y pujanza. Se refirió a los componentes religiosos, la doctrina darwinista, el laissez-faire como sustentación socioeconómica y la idea de frontera como ideología impulsora. El espíritu crítico de la exposición se completó con la discusión de la teoría sociológica impulsada por los profesores Arcondo, David, Clementi y Etchepareborda. 


\section{REFLEXIONES FINALES}

La ponencia del Profesor Ely parece encuadrarse en la política del gobierno estadounidense de la "buena vecindad", expresión que, de hecho, figura en su título. Como comentario y reflexión final, luego del trabajo empírico e interpretativo, resta plantear la correlación que surge entre la política y la historia, o entre la parte I y II de la ponencia del profesor Ely. De la mano del programa académico aparecen las intenciones no académicas, por llamarlas de algún modo, o más políticas, geopolíticas o de relaciones internacionales. Lo académico (los cursos y las jornadas) resultará una puerta de entrada para la penetración de la política y de la dominación cultural. En este momento, de "nuevos enfoques o investigación de nuevos temas, debates y disensos", el campo historiográfico y el campo político aparecen atravesados por una coyuntura muy especial, como ya fue referido en otras partes de este trabajo. Lo que además queremos postular es que la coyuntura especial se refleja recíprocamente en ambos campos. El campo historiográfico argentino, como refiere Eduardo Míguez (1993), había transitado por una transformación desde los historiadores sociales, los trabajos de historia económica y social ya habían empezado a producirse entre nuestros historiadores, siguiendo los lineamientos de la historiografía francesa de Annales. NHE, históricamente hispanista y dedicada a la historia política, deja entrar la historia de Estados Unidos al Instituto de Investigaciones Históricas de la Facultad de Filosofía y Letras de la Universidad de Buenos Aires, en el mismo momento en que Argentina se alinea geopolíticamente con el "Coloso del Norte" (parafraseando al Profesor Ely) en pleno contexto de la Guerra Fría, adhiriendo y aplicando la Doctrina de la Seguridad Nacional. Las "buenas intenciones" académicas del Profesor Ely para renovar la enseñanza de la historia con nuevos enfoques encubren en verdad la necesidad de EEUU de influir culturalmente en la región latinoamericana. Lejos está de ser una renovación de enfoques y métodos la enseñanza de una historia de los Estados Unidos sobre la base de traducciones y resúmenes que se brinda a los estudiantes argentinos, con guías y modelos de exámenes dirigidos y discusiones pautadas. Si bien esto puede ejercitar el pensamiento crítico, sólo lo hace a nivel del entrenamiento intelectual pero no cumple el objetivo fundamental del pensar e investigar históricamente. Y no lo cumple desde el momento en el que está vedado el acceso directo a la versión original de la bibliografía. Las razones que da Ely resultan un tanto ingenuas: inaccesibilidad por el idioma o por los costos.

Por lo tanto, la coyuntura política y el viraje de Argentina hacia la órbita de Estados Unidos en sus relaciones internacionales, parecería también reflejarse en el campo historiográfico (Rodríguez y Sauro, 2017). La dictadura de Onganía y la Noche de los bastones largos cambian el rumbo de la historia universitaria. En el caso de la Carrera de Historia se frustra el proyecto renovador del contexto de los 50 y 60 cuyo eje fue la historia económica y social y los aportes de las Ciencias Sociales. Por lo tanto, la incorporación de temas de historia económica y social en la formación de sus estudiantes y graduados que propicia NHE tendrá como referente a la historiografía norteamericana, sin que esto signifique un desplazamiento de los temas políticos. Por el contrario, los estudios tradicionales de historia política de los profesores más antiguos a cargo de las cátedras y de los proyectos de investigación seguirán siendo los más elegidos.

Sumando a lo anterior, en estas jornadas se identificó la presencia de ponentes que no habían recibido los cursos y seminarios del Profesor Ely, a pesar de lo cual contribuyeron con valiosos trabajos económicosociales, promoviendo incluso acalorados debates según consta en las actas correspondientes. ¿Es posible que estos trabajos fueran producto de la experiencia de la historia social practicada por el grupo renovador en clave de los paradigmas de Annales o del Marxismo? ¿Estos trabajos resultan ser un resabio de aquella experiencia? Futuras investigaciones podrán profundizar lo que surge del relevamiento empírico y solamente se esboza como hipótesis.

Queda abierta la pregunta acerca de cuál fue el beneficio que recibió NEH. Sin duda para sus discípulos y ayudantes de investigación fue una puerta de acceso a pasantías y estudios de posgrado en EEUU. ¿Esto de por sí posiciona en el nivel corporativo internacional a los miembros de NEH? No parece del todo convincente dado que en este orden, la hegemonía de la tradición historiográfica francesa recién se ponía 
en disputa por los historiadores norteamericanos, que comenzaban a difundir sus producciones bajo nuevos criterios. (Noiriel, 1997) De ahí que, la estrategia académica del Profesor Ely puede interpretarse desde otra de las matrices de pensamiento fuertes de los años 60, que además tuvo una particular resonancia en la comunidad científica argentina: el cientificismo (Varsavsky, 1969). ${ }^{13}$ De alguna manera, el programa de intercambio que introdujo Ely impuso una agenda de temas y de enfoques, para formar, hacer y pensar a los alumnos argentinos la historia de Estados Unidos, e influir en los historiadores argentinos con esa agenda. Los historiadores argentinos introdujeron en sus investigaciones los temas y problemas que a Estados Unidos le interesaba que se estudiaran: temas de frontera, influencias de la Constitución norteamericana en los procesos de independencia americana; intervencionismo económico; revolución industrial; inmigración y esclavismo. La estrategia de "buenos vecinos" supone que se pueda "compartir", establecer relaciones históricas y compararlas. Consecuentemente, esto trae relaciones de sociabilidad, académicas y corporativas, materializadas en seminarios, cursos y jornadas

Si bien los fundadores de la NEH provenían del campo del derecho y produjeron una historia en clave de la institucionalización política del pasado argentino, sentaron las bases de la profesionalización en el campo de la Historia. Por lo tanto, hacia 1960 los historiadores profesionales han engrosado el número de historiadores de la NEH. Sin embargo, la historia que practicaban seguía respondiendo a los cánones pautados por sus referentes de la década de 1920. La historia profesional crítica consustanciada con los nuevos tiempos de los años 60, se había interrumpido en la coyuntura del 66 y no había permeado a los historiadores de la nueva escuela (Devoto, Pagano, 2009). De ahí que el mayor rédito para NEH parecería haber sido en el orden local, reforzando su hegemonía en las instituciones del quehacer histórico, academia y universidades, y ofreciendo al poder político una narrativa histórica que obre de historia oficial.

Sobre la base de estos comentarios y analizando la ponencia del Prof. Ely, nuestro trabajo intentó proponer una interpretación de este contexto político institucional e historiográfico. La introducción de la enseñanza e investigación de la historia de Estados Unidos puede leerse como un programa académico que resulta empático con la bisagra histórica que inaugura la Noche de los Bastones Largos, el fortalecimiento del discurso militarista de la ideología de derecha representado por la Doctrina de la Seguridad Nacional y la identificación de la Universidad como un centro de infiltración comunista y guerrillera. Las Jornadas, apoyadas y promovidas por los historiadores eruditos de NEH ininterrumpidamente entre 1966 y 1971 pueden interpretarse además desde el aspecto geopolítico de la dictadura de Onganía y funcional con el nuevo período institucional. Pero en el campo estrictamente historiográfico, deberían entenderse como una estrategia para reafirmar y consolidar el terreno institucional ganado a los historiadores sociales en las Universidades Argentinas. Es decir, NEH vuelve a legitimarse en el quehacer histórico controlando las instituciones y las relaciones políticas y académicas del orden local y su vinculación con el internacional occidental dominante.

No es menos cierto que parecería aflorar en estas Jornadas la impronta que había dejado el grupo renovador en algunos graduados y estudiantes durante los años de la Universidad Reformista de los años 58/65. No todos los representantes de la Universidad del Sur y de Córdoba habían recibido los cursos y seminarios del Profesor Ely. No obstante aportaron trabajos interesantes de historia económica y social, tal como aparece comentado en las actas publicadas en el Boletín. ¿Será que esa renovación en las formas de hacer historia de los historiadores sociales haya quedado latente por dos décadas, aguardando una nueva coyuntura para disputar con otros resultados la hegemonía de $\mathrm{NEH}$ ? ¿Será que la profesionalización de los años de la historiografía reciente post 1985 se deba a otras razones fundacionales de mayor envergadura y complejidad?

\section{Referencias Bibliográficas:}

Buchbinder, P. (1997) Historia de la Facultad de Filosofia y Letras. Universidad de Buenos Aires, Eudeba, Buenos Aires, caps. XIII-XVI. 
Devoto, F. (1994) "Los estudios históricos en la Facultad de Filosofía y Letras entre dos crisis institucionales (1955-1966)" en La historiografia argentina en el siglo XX, T II, CEAL, Buenos Aires, p. 50-65.

Devoto F. y Pagano, N. (2009) Historia de la Historiografia Argentina, Buenos Aires, Sudamericana.

Dowker, G. (1991) “¿Ciencia universitaria o industrial? El auge de la investigación industrial”. En Serrés, Michel. Historia de las ciencias. (s/l): Cátedra.

Míguez, E. (1994) "El paradigma de la historiografía económico social de la renovación de los años 60, vistos desde los años 90" en Devoto, F.: (comp.) La historiografia argentina en el siglo XX, Buenos Aires, CEAL. vol. 2, pp. 10-29.

Halperín Donghi, T. (1998) Historia Contemporánea de América Latina. México. Alianza Editorial.

Hobsbawm, E., (1999) “Brujos y aprendices: las ciencias naturales”, en Historia del siglo XX, Buenos Aires, Crítica, $3^{a}$ reimpr.pp. 516-50;

Iggers, G. (1995): La ciencia histórica en el siglo XX. La ciencia histórica en el siglo xx. Las tendencias actuales. Una visión panorámica y critica del debate internacional. Idea Books, Barcelona.

Medina, M. y Sanmartín, J. (Eds.) (1990): Ciencia, tecnología y sociedad. Barcelona, Anthropos.

Noiriel, G.: (1997) Sobre la crisis de la historia. Madrid. Cátedra. Cap. 1 y 2.

Pietschmann, H. (2000) "La historia de América Latina como subdisciplina histórica", en Anuario IEHS: Instituto de Estudios histórico sociales, ISSN 0326- 9671, N. 15.

Pita González, A. y Ventura Ramírez, R. “La convención sobre la enseñanza de la Historia: educar para la comprensión americana”. https://studylib.es/doc/1332275/la-convención-sobre-la-enseñanza-de-la-historia.

Riquelme, G. (ed.) (2008): Las universidades frente a las demandas sociales y productivas. Tomo I, Buenos Aires, Miño y Dávila Editores.

Rodríguez, M. (2016) "Los historiadores, las conmemoraciones y su celebración. El IV Congreso Internacional de Historia de América y el Sesquicentenario de la independencia”. Jornadas. 200 años. Independencias, guerra y nuevos órdenes en América. Los tiempos convulsionados, las ideas y sus resonancias. Buenos Aires: Facultad de Ciencias Sociales. UBA, 2016. (Mineo)

Rodríguez, M y Saura, S. (2017) “Congresos, redes académicas y conmemoraciones: entre la historia y la política de la historia en la Argentina del Sesquicentenario de la Independencia”. GT 11. La historiografía en los Estados de la Cuenca del Plata (siglos XIX y XX). Configuraciones, itinerarios, intercambios. Jornadas Académicas 2017 Profesor Washington Benavidez (VII Jornadas de Investigación, VI Jornadas de extensión y V Encuentro de Egresados y Maestrandos) de la Facultad de Humanidades y Ciencias de la Educación de la Universidad de la República. Montevideo, 11, 12 y 13 de octubre de 2017. (Mimeo)

Rodríguez, M. (2018). De historiadores y de los posibles usos de su saber: la contribución de los Congresos Internacionales de Historia de América en la conformación de una identidad americana (décadas de 1930 a 1960). Consultado en: https://www.historiadahistoriografia.com.br/revista/article/download/1368/732

Saldaña, J.J. (coordinador) (1996): Historia social de las ciencias en América Latina. Porrúa Grupo Editor, 1996

Sauro, S (2018) “La creación de la Sección de "Documentación Extranjera” en el Instituto de Investigaciones Históricas "Dr. Emilio Ravignani” (mimeo. Presentado en las VIII Jornadas de la División Historia "En el Centenario de la Reforma Universitaria". UNLU, 7 y 8 de noviembre de 2018. (Mimeo)

Solís, C. y Sellés, M., (2005) Cap. 29 "La ciencia del siglo XX”, en Historia de la ciencia, Madrid, Espasa-Calpe, Cap. 25 , pp. $983-1010$

Tcach, C. (2007) “Golpes, proscripciones y partidos políticos" en James, D. (coord.) Violencia, proscripción y autoritarismo. Buenos Aires, Sudamericana. IX Nueva Historia Argentina, cap. 1

Varsavsky, O. (1969): Ciencia, politica y cientificismo. Buenos Aires. CEAL.

\section{FUENTES PRIMARIAS:}

Boletín del Instituto de Historia Argentina. Año X, T X (segunda serie), Buenos Aires, 1968. No 16-17; pag. 172-174 Boletín del Instituto de Historia Argentina. Año XI, T XI (segunda serie), Buenos Aires, 1969. No 18-19; p. 182-201. 
Boletín del Instituto de Historia Argentina. Año XII, T XII (segunda serie), Buenos Aires, 1969. № 20-21; pag. 262-265.

Boletín del Instituto de Historia Argentina. Año XIII, T XIII (segunda serie), Buenos Aires, 1970. No 22-23; pag. $336-337$ y $337-348$.

Boletín del Instituto de Historia Argentina. Año XIV, T XIV (segunda serie), Buenos Aires, 1970/71. o 24-25, Buenos Aires, 1973; pag. 236-239.

Archivo Documental Instituto Ravignani (AIR) - Correspondencia 1965-1966: Folio 133, 12/05/1966; Folio 238, 27/4/1966. C 93.

Archivo Documental Instituto Ravignani (AIR) - Carpeta Resoluciones Consejo Directivo- FFyL- 1965-1966. Folio 72 a $84,28 / 12 / 1965$. C116

\section{Notas}

1. En otro trabajo me he ocupado de la relación del Instituto de Investigaciones Históricas "Dr. Emilio Ravignani" con Günter Khale, profesor de la Universidad de Colonia.

2. Ver en este mismo Dossier el artículo de Martha Rodríguez

3. Ver en este mismo Dossier el artículo de Nora Pagano.

4. (AIR, Folio 218, 27/12/1965 - C93)

5. (AIR, Folio 72 a $84,28 / 12 / 1965-$ C116)

6. (AIR, Folio 238, 27/04/1966-C93)

7. (AIR Folio 133, 12/5/1966 - C93)

8. (AIR 93/ Folio 238, 27/4/1966)

9. Segundas Jornadas de Métodos de Investigación y de la Enseñanza de la Historia y de la Literatura Rioplatense y de los Estados Unidos. Boletín del Instituto de Historia Argentina. Año X, T X (segunda serie), Buenos Aires, 1968. № 16-17; pag. 172-174

10. Caillet Bois, R.: IV Jornadas de Investigación en Historia y Literatura Rioplatense y de los Estados Unidos. Boletín del Instituto de Historia Argentina. Año XII, T XII (segunda serie), Buenos Aires, 1969. № 20-21; pag. 262-265)

11. Información General. V Jornadas de Métodos de Investigación y de la Enseñanza de la Historia y de la literatura Rioplatense y de los Estados Unidos. Boletin del Instituto de Historia Argentina. Año XIII, T XIII (segunda serie), Buenos Aires, 1970. № 22-23; pag. 336-337 y Actas de la Comisión de Historia de las V Jornadas de Historia y Literatura Argentina y Norteamericana, agosto de 1970, p. 337-348, por Hebe Clementi

12. Información General. VI Jornadas de Métodos de Investigación y de la Enseñanza de la Historia y de la literatura Rioplatense y de los Estados Unidos. Boletín del Instituto de Historia Argentina. Año XIV, T XIV (segunda serie), Buenos Aires, 1970/71. No 24-25, Buenos Aires, 1973; pag. 236-239

13. Uso cientificismo en los términos expresados por Varsavsky. Si bien su obra fue publicada en 1969, desde 1959/60 comienza a crearse un clima que desatará en los años siguientes un polarizado debate en la Universidad de Buenos Aires, que se inicia especialmente en la Facultad de Ciencias Exactas y Naturales y se continúa en la de Medicina. El grupo reformista que ocupaba los cargos directivos comienza a ser denominado "cientificista" por un sector estudiantil y docente pro-marxista. El debate atraviesa los años 60 y primera mitad de los 70 siendo una de las premisas el financiamiento extranjero y los intereses universalistas de la ciencia que condicionan la agenda de investigación y afectan los intereses nacionales. 